\title{
Design of Reduced Graphene Oxide Based Piezo-Resistive Type Acoustic Sensor on Flexible Kapton for Underwater Applications
}

\author{
B. Smitha Pai ${ }^{*}$, M. A. Goutham², Veera Pandin ${ }^{3}$ \\ ${ }^{1}$ Department of ECE, Nitte Meenakshi Institute of Technology, Bangalore, India \\ ${ }^{2}$ Department of ECE, Adichunchanagiri Institute of Technology, Chikmagalur, India \\ ${ }^{3}$ Centre for Nano Science and Engineering, Indian Institute of Science (IISc), Bengaluru, India \\ Email: *smitha.prabhu@nmit.ac.in, magoutham@yahoo.co.in, veerapandin89@gmail.com
}

How to cite this paper: Pai, B.S., Goutham, M.A. and Pandin, V. (2019) Design of Reduced Graphene Oxide Based Piezo-Resistive Type Acoustic Sensor on Flexible Kapton for Underwater Applications. World Journal of Engineering and Technology, 7, 339-353.

https://doi.org/10.4236/wjet.2019.72025

Received: April 1, 2019

Accepted: May 27, 2019

Published: May 30, 2019

Copyright $\odot 2019$ by author(s) and Scientific Research Publishing Inc. This work is licensed under the Creative Commons Attribution International License (CC BY 4.0).

http://creativecommons.org/licenses/by/4.0/

\begin{abstract}
Micro Electro Mechanical Systems (MEMS) vector sensor is a recent advancement in the field of underwater acoustic sensors. The major incentive provided by this acoustic vector sensor is that it provides information about the direction of the incoming acoustic source signal in addition to the measurement of the pressure associated with the acoustic signal. We are reporting a design of a MEMS acoustic vector sensor for underwater applications using piezoresistive film of Reduced Graphine Oxide (RGO), realized on kapton (polyimide) film as the starting material. The sensor is designed and fabricated by deposition of RGO on a kapton, which is a flexible substrate by the method of drop casting making the process simple, low-cost and scalable. The application of the piezoresistive transduction principle and ingenious structure of the vector sensor based on bionic principle improves miniaturization and the low-frequency sensitivity. The fabricated sensor shows a repeatable response in both static and dynamic conditions, to the applied strain due to the acoustic signal in a given direction. The experimental results show that fabricated sensor based on MEMS technology and piezoresistive effect is feasible and it possesses intrinsic two-dimensional directivity. The fabricated device has given good response for the low-frequency acoustic signals due to the effect of piezoresistive transduction principle and the resonance frequency of the device is found to be around $80 \mathrm{~Hz}$ with the displacement sensitivity around $3 \mathrm{mV} / \mathrm{mm}$ and $2 \mathrm{mV} / \mathrm{mm}$ of $\mathrm{X}$ and $\mathrm{Y}$ axis directions respectively.
\end{abstract}

\section{Keywords}

Micro Electro Mechanical Systems (MEMS), Reduced Graphine Oxide (RGO), Piezoresistive, Acoustic Vector Sensor, Plastic Rod, Microstructure 


\section{Introduction}

As sound wave is an effective means of disseminating and transmitting information in nature for underwater operations, underwater acoustic acts as the main means of target identification, navigation and communication [1]. Acoustic wave is a sound wave in an elastic medium. The mechanical perturbation or disturbance in water leads to the generation and propagation of wave from origin. The restoring force is exerted due to the compression and rarefaction of the molecules of water and it resists the motion. The restoring force is realised as pressure. Frequency and pressure are the two main fundamental parameters of sound wave [2]. The generated noise in water and the variations in pressure of sound signal are detected by hydrophone and it produces equivalent electrical voltage which is proportional to the applied pressure. The traditional hydrophone can obtain only scalar information associated with the sound wave such as pressure. But it cannot obtain vector information such as direction of the sound field. As in recent years the noise radiated by submarine has reduced drastically, the application of acoustic vector sensor effectively suffices the requirement of submarine sound detection. This device can obtain the pressure of the sound and direction of the sound field simultaneously [3]. The vector sensor composed of array of scalar hydrophones results in disadvantage of having larger volume, compromising in consistency. Majority of hydrophones work on the principle of piezoelectric transduction principle. The benefit of using piezoelectric material as sensing material is that it gives better signal-to-noise ratio due to its piezoelectric property and its structural strength has the capacity to sustain the surrounding water pressure but it will not be able to detect low-frequency signals [4]. With the continuous development in the area of underwater acoustical technology and warfare, the frequency of the noise radiated by underwater motion platform belongs to lower frequency band. In order to detect these low-frequency signals, single vector acoustic sensor based on bionic principle, piezoresistive principle and MEMS technology was developed by North University of China [5]. The vector acoustic sensor was developed based on the advancement in MEMS technology, semiconductors and integrated circuits. The advantage of this MEMS vector acoustic sensor is that, they are light weighted, compact and possesses better sensitivity [6]. This MEMS-based vector sensor based on piezoresistive transduction principle operates at low frequencies with comparatively small dimensions and it possesses intrinsic two-dimensional directivity [7]. Advantage of piezoresistive transduction principle is that it can suffice the requirement of detecting and responding to acoustic signals of lower frequencies [8].

To work with sensors, Shang Chen et al. [8] [9] used p-type silicon as substrate and piezo-resistive material doped poly-silicon as sensing material to achieve higher sensitivity, two directional directivity and for low frequency detection. But conventional technology uses silicon as substrate which is not flexible and is made flexible by the process of mechanical-chemical polishing to reduce the thickness of silicon substrate to the level of submicron thickness. This 
process is challenging and involves high cost. In addition, the fabrication process requires facilities of clean room and involves several days.

In the past decade, the extensive efforts of researchers resulted in finding efficient nano scale materials with minimum cost which exhibits considerable structural changes for the applied strain. Recently graphene material has taken lead role and makes it suitable for pressure sensing applications due to their chemical, electronic, mechanical and physical properties [10]. Graphene, being one of the classes of carbon family consists of just a single layer of carbon atoms. This monolayer arrangement gives extraordinary thinness to graphene membranes and they react to exerted forces with great sensitivity. Graphene membrane has higher carrier mobility and mechanical stability. Also, due to its extreme thinness a minor variation in applied pressure is sufficient to deflect the membrane and cause change in electronic properties [11]. There exists a linear relationship with strain and resistivity of graphene. By virtue of all these properties, the graphene as a material can be used in all applications of electronic and sensing fields to yield better performance [12].

In this paper, an attempt is made to design and develop a biologically inspired (fish cilia) two-dimensional acoustic vector sensor based on MEMS technology and piezoresistive transduction principle, which is suitable for underwater applications. The proposed acoustic sensor uses highly flexible kapton as starting material for substrate and a thin film of graphene with remarkable piezorestive property as a sensing material, which is realised on flexible substrate by drop casting method. The flexibility, uniform thickness of the membrane makes it perfect for sensing structure and piezoresistive effect of graphene is used to connect electrical and mechanical domains. The device exhibits two-dimensional directivity, thereby overcoming the limitations of the scalar hydrophone and it also detects signals with low frequency. Therefore combining the advantages of both MEMS technology and piezoresistive effect of RGO with unique electronic properties has great significance, as it results in simple, low cost and scalable process.

\section{Sensor Design}

The structure of acoustic vector sensor mainly has two parts: 1) Micro-structure with 4 horizontal cantilever beams (175 $\mu$ m thickness) 2) The rigid plastic rod as shown in Figure 1. The plastic rod should be attached to the center of the microstructure and the density of plastic rod should match the density of the considered elastic medium i.e. water. The thickness of the center block and the horizontal cantilever beam should be same and they should have axial symmetry.

When plastic rod is subjected to axial or radial stress, the central mass will experience a horizontal displacement which leads to the angular rotation of the same. Due to the deformation of the structure, the sensing beams will experience an effect of amplified strain on them. The placed piezoresistors on the sensing beams convert the induced stress into corresponding variations in the electrical 
resistance for the applied pressure. These variations in the electrical resistance can be converted into output voltage by forming Wheatstone bridge on sensing beam as shown in Figure 2. The deformation of the beam is sensed by eight piezoresistors (R1, R2, R3, R4 \& R5, R6, R7, R8) which are placed on beam and connected in wheatstone bridge configuration.

The resistance of the piezoresistors will vary for the transmitted acoustic signal and results in corresponding electrical output voltage.

\section{Modelling Using Comsol Multiphysics}

The sensor geometry is modelled using Solid mechanics physics and stationary study of Comsol Multiphysics 5.0. The 3D geometry comprises three main components including a microstructure, central block and a plastic rod as depicted in

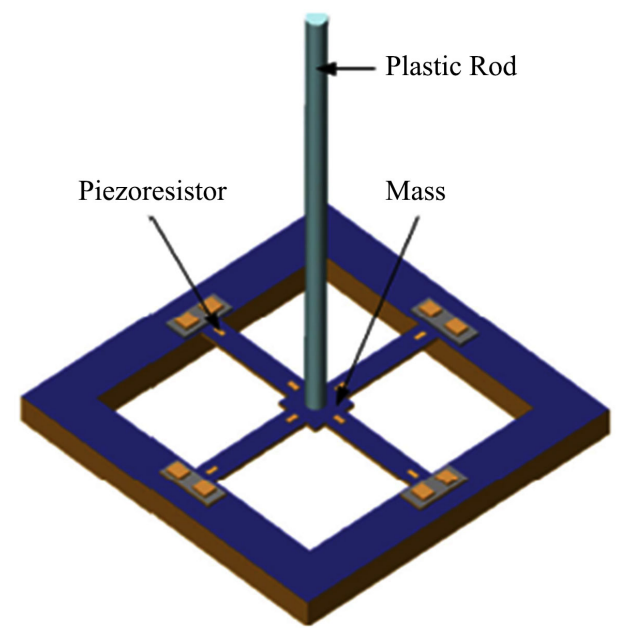

Figure 1. 3D model of structure of acoustic vector sensor where plastic rod is attached at the central mass and when subjected to mechanical stimiulus, provides electrical output voltage using piezoresistors provided on 4 horizontal beams in wheatstone bridge configuration.

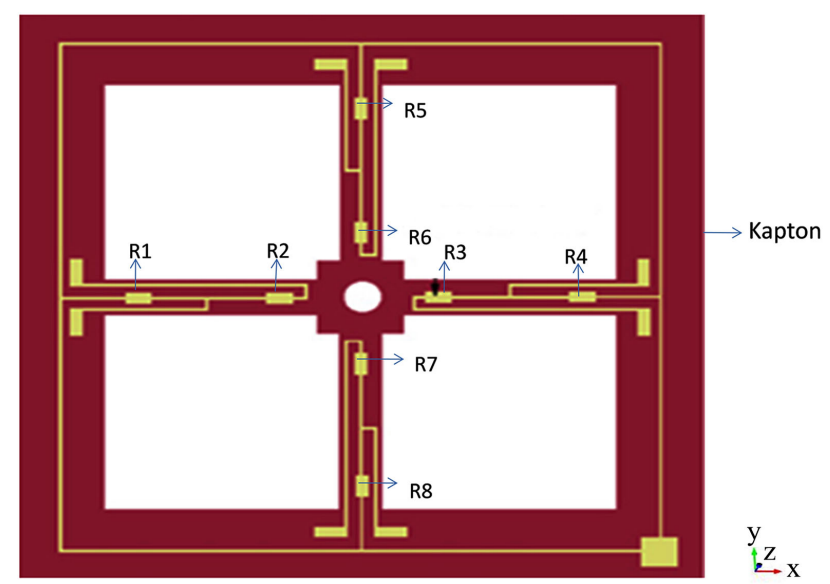

$R 1, R 2, R 3, R 4, R 5, R 6, R 7, R 8:$ Piesoresistos

Figure 2. 2D top view of the acoustic vector sensor, where the piezoresistors R1, R2, R3, $\mathrm{R} 4$ of $\mathrm{X}$ direction and R5, R6, R7, R8 of Y direction are linked by full wheatstone bridge. 
(Figure 1). The material used to form microstructure and central block is Kapton with density of $1300 \mathrm{Kg} / \mathrm{m}^{3}$, Relative permittivity of 2.9 , Young's modulus of 3.1 Gpa and Poisson's ratio 0.34 and Nylon for plastic rod with Poisson's ratio 0.4. The Parametric analysis is carried out and as per the study the length, width, thickness of 4 beams are $10 \mathrm{~mm}, 2 \mathrm{~mm}$ and $0.175 \mathrm{~mm}$ respectively. The square central block is $6 \mathrm{~mm}$ with rod dimensions being $25 \mathrm{~mm}$ length and $2 \mathrm{~mm}$ in diameter.

One of the ends of all four cantilever beams of 4 beam microstructure is attached to the central block and the other end is made fixed by attaching it to the support frame. Simulation is carried out in order to study the behaviour of the structure for the applied boundary load. Here, the boundary load is taken as pressure and when it is applied on the plastic rod, central block will undergo angular displacement. The structure will experience deformation as shown in Figure 3, which results in the generation of amplified strain. Maximum stress is observed at the support frame and the beam central mass interface as shown in Figure 4. The piezoresistors should be placed on the beam where there exists maximum stress as shown in Figure 5. Dynamic characteristics of the designed structure are studied to determine vibration characteristics. To find the different instants or periods at which the structure will resonate naturally, the dynamic analysis uses the stiffness and mass of the device. Figure 6(a) shows the natural frequencies of the device from the first mode to sixth mode. The first and the second mode frequencies are $70.474 \mathrm{~Hz}$ and $70.519 \mathrm{~Hz}$ respectively, both of them being the structure operating frequencies as shown in Figure 6(b).

\section{Fabrication Process of Structure}

The device fabrication mainly consists of realisation of microstructure with four horizontal beams and attaching rigid plastic rod to the structure as shown in Figure 7. The microstructure is realised on a square Kapton (polyimide) flexible substrate of thickness $175 \mu \mathrm{m}$ and $50 \mathrm{~mm}$ diameter, by processing it through laser cutting procedure as shown in Figure 7(a). For strain sensing, the piezoresistive film of RGO is realised on 4 beams of the flexible microstructure by the method of drop casting and further it is annealed in oven at 120 degree Celsius for 1 hour (Figure 7(b)). This result in coating of RGO on the four beams of diaphragm whose resistivity can be measured. To establish electrical connections with the device the leads are taken out by forming contact using silver paste as shown in Figure $7(\mathrm{c})$. Device is then coated with a polymer viz., perylene, to protect it from external moisture. Also, it reduces the risk of breakage of the coating of RGO during vibration. After the realisation of the micro-structure a plastic rod is attached at the central mass of using Araldite adhesive and is as shown in Figure7(d).

\section{Calibration}

The characterization of an acoustic vector sensor mainly refers to the sensitivity 
and directivity. For this analysis, two wheatstone bridges were formed along axial (X axis) and radial direction ( $\mathrm{Y}$ axis) of the structure on the beams as shown in Figure 8.

$\mathrm{X}$ and $\mathrm{Y}$ axes Wheatstone bridges are formed by Piezoresistors R1, R2, R3, R4 and $\mathrm{R} 5, \mathrm{R} 6, \mathrm{R} 7, \mathrm{R} 8$ respectively. The device was calibrated by using both static and dynamic calibration methods.

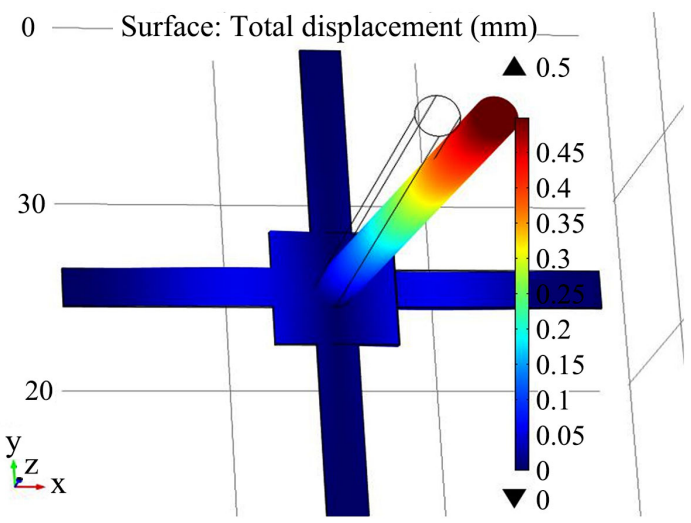

Figure 3. Displacement along the plastic rod and deformation of the stucture for applied pressure of $120 \mathrm{~Pa}$.

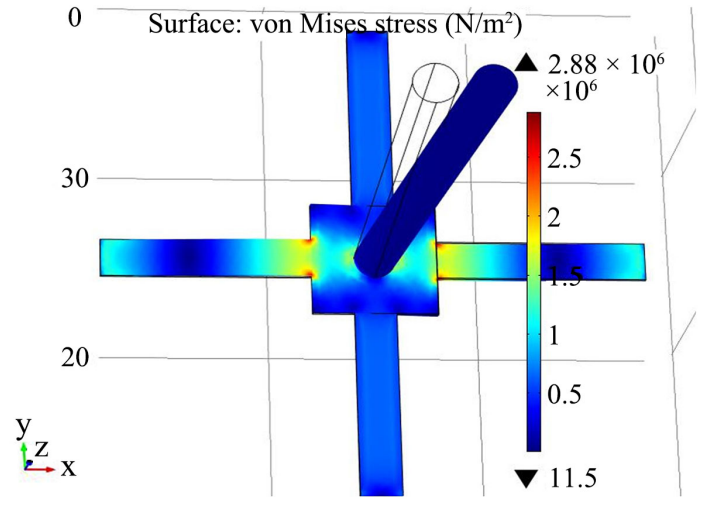

Figure 4. The stress distribution on 4 horizontal cantilever beams of structure due to structure deformation for applied pressure of $120 \mathrm{~Pa}$.

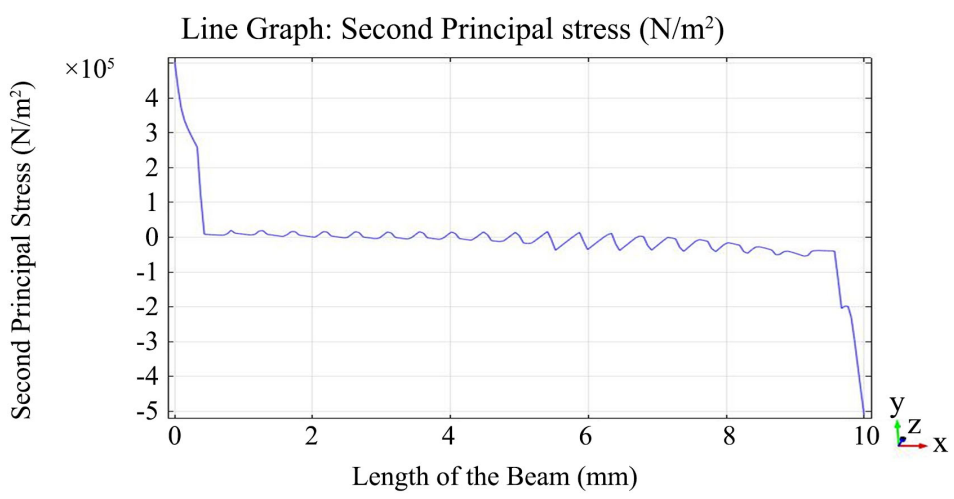

Figure 5. Stress distibution along single horizontal cantilever beam along X direction to get the optimium location for the placement of piezoresistor on the beam. 


\begin{tabular}{l|l}
\hline Eigenfrequency: & 70.519 \\
\cline { 2 - 2 } & 70.474 \\
\hline \multirow{2}{*}{ Expression } & 70.519 \\
\hline Expression: & 155.87 \\
\hline solid.disp & 2076.6 \\
\hline Unit: & 2078.1 \\
\hline $\mathrm{mm}$ & 2101.3 \\
\hline
\end{tabular}

(a)
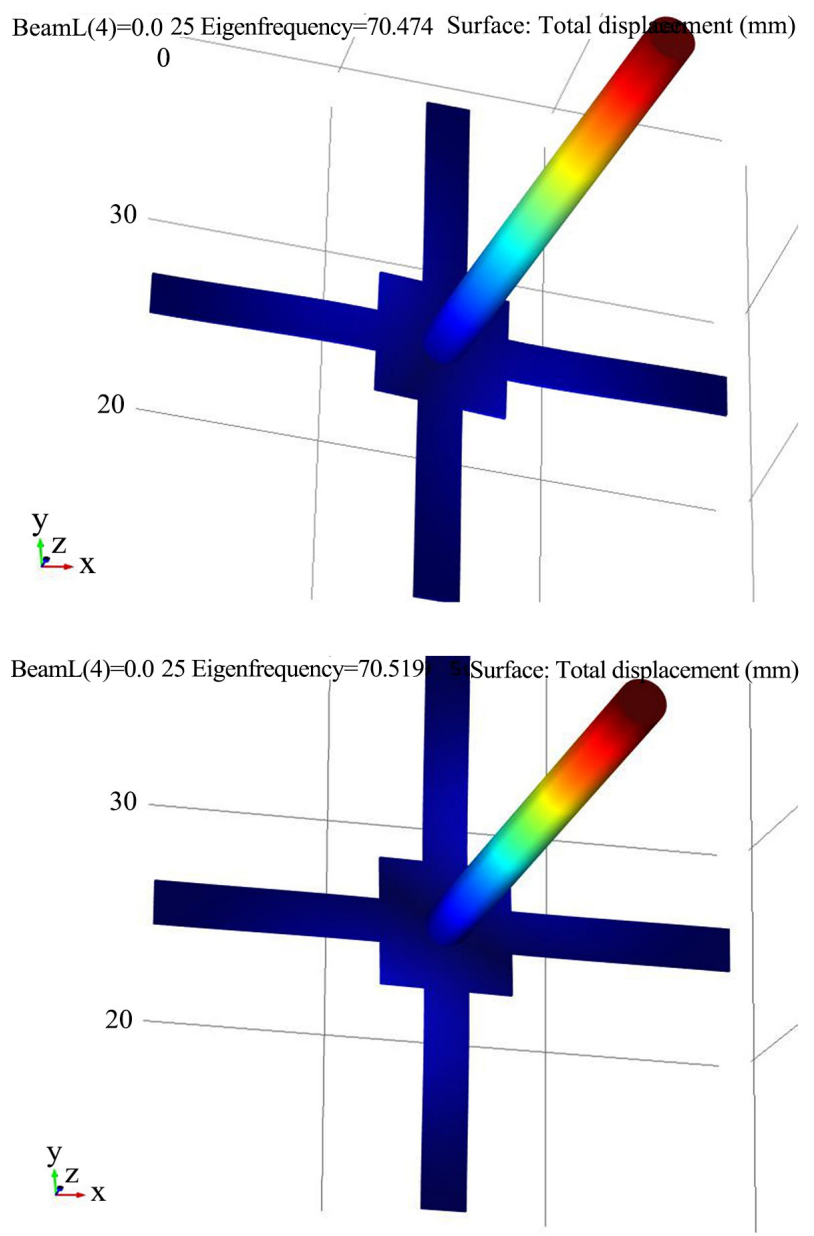

(b)

Figure 6. The first step of dynamic analysis is the modal analysis to find the mode shapes and the natural frequencies of the structure. (a) Six natural frequencies of the structure and (b) The corresponding first two modes shapes of structure.

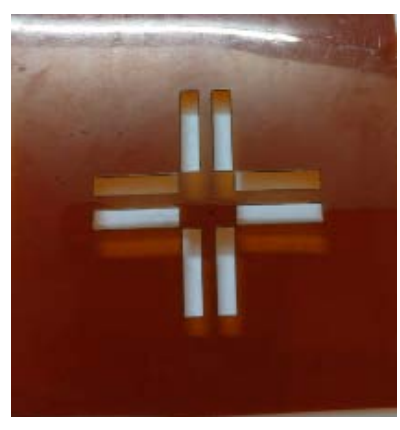

(a)

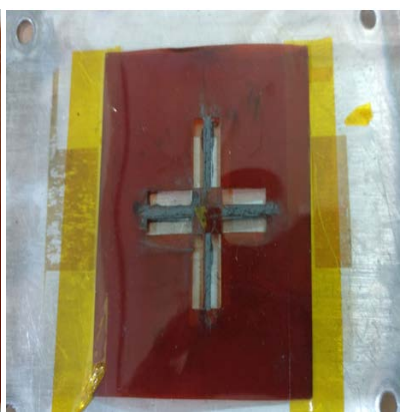

(b) 


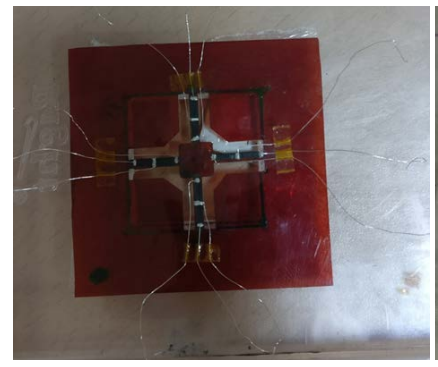

(c)

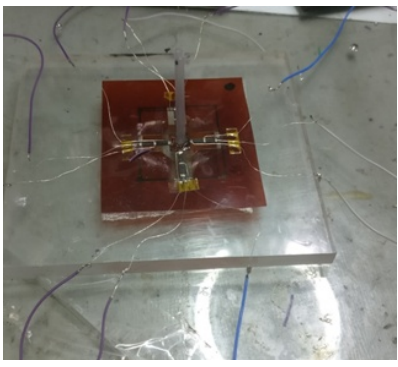

(d)

Figure 7. Schematic process steps to fabricate acoustic vector sensor. (a) 4-Beam Microstructure: Flexible Kapton sheet of 175 um thickness is taken as starting material of substrate and 4 horizontal cantilever beams of length $10 \mathrm{~mm}$ and square central mass of 6 $\mathrm{mm}$ are formed by processing substrate through laser cutting procedure; (b) Deposition of RGO: Mask is prepared by using stainless steel material of thickness 15 um and length $10 \mathrm{~mm}$ and it is fixed on each beam and RGO is deposited by drop casting method; (c) Formation of electrical contact: To have electrical connection on each beam three leads are taken out by using silver paste; (d) Fixing Plastic Rod: Plastic rod is fixed at the central mass to receive mechanical stimulus.
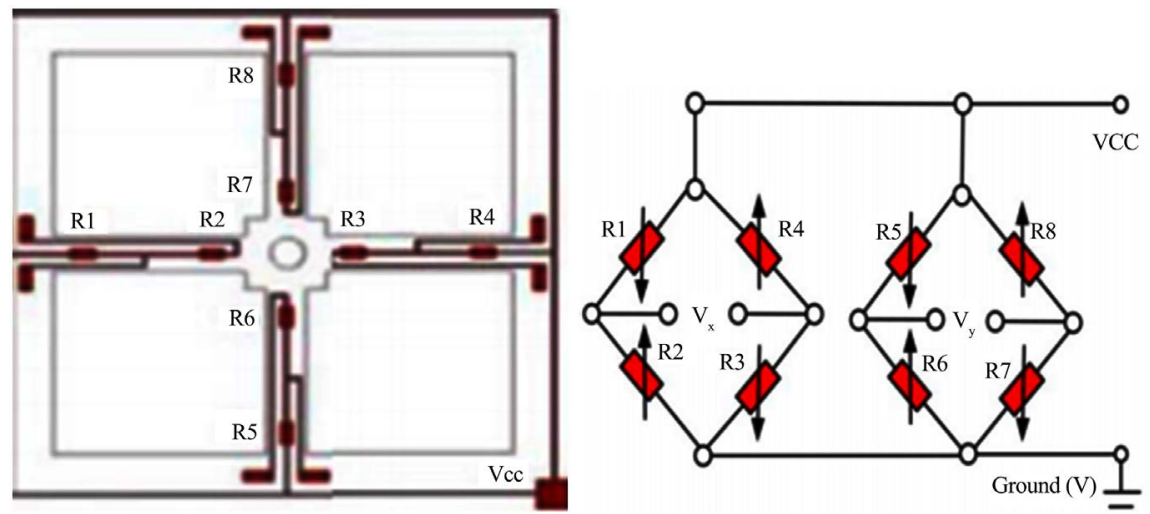

Figure 8. For sensitivity and directivity analysis, two wheatstone bridge were formed on beams along $\mathrm{X}$-axis and $\mathrm{Y}$-axis directions using eight piezoresistors.

\subsection{Static Calibration}

To study and analyse the performance, the device was fixed on vice and a plastic rod was used in configuration of cantilever as mentioned in Figure 9. Digital height gauge was used to apply force to the free end of the rod to displace it in a particular direction by certain magnitude. The complete experimental setup used is as shown in Figure 9. Strain sensor electrical leads are connected to digital multimeter. Strain was exerted on sensor by the application of the force on free end of the plastic rod. For the given displacement by the digital height gauge to the free end of the plastic rod there will be corresponding resistance variation of the gauge and the same was noted using digital multimeter.

When a radial force was applied on the plastic rod in the $\mathrm{Y}$ direction, the beams which are situated along the $\mathrm{Y}$ direction will undergo deformation due to the compressive and tensile stresses acting along the beam, which results in corresponding resistance variation of the beam. The wheatstone bridge formed 
along the $\mathrm{Y}$ axis will give the equivalent electrical output voltage, which indicates the direction of the exerted force as radial direction i.e. as $+\mathrm{Y}$ direction. The opposite will happen for the force which is in the negative radial direction. Similarly when the plastic rod was applied force in the $\mathrm{X}$ direction, the beams which are situated along the $\mathrm{X}$ direction will undergo deformation due to the compressive and tensile stresses acting along the beam, which results in corresponding resistance variation of the beam. The Wheatstone bridge formed along the $\mathrm{X}$ axis will give the equivalent electrical output voltage which indicates the direction of exerted force as axial direction i.e. as $+\mathrm{X}$ direction. The opposite will happen for the force which is in the negative axial direction. Figure 10 shows the variation of resistances R5, R6, R7 and R8 with respect to various displacements caused due to the applied force in negative $\mathrm{Y}$ direction.

Output Voltage of $\mathrm{Y}$ axis Wheatstone bridge with the applied excitation voltage of $3 \mathrm{~V}$ for various displacements of plastic rod in positive \& negative $\mathrm{Y}$ direction is shown in Table 1.

The sensitivity shown by the corresponding $\mathrm{Y}$ axis Wheatstone bridge was found to be around $2 \mathrm{mV} / \mathrm{mm}$. Here the offset output voltage was found to be $356.60 \mathrm{mV}$. When the plastic rod was subjected to displacement $(\mathrm{mm})$ by applying force in negative $\mathrm{Y}$ direction, the electrical output voltage of the corresponding bridge was found to be decreasing as mentioned in Table 1 and opposite was observed for force when it was applied to the rod in positive $\mathrm{Y}$ direction.

The similar effect was observed when the plastic rod was subjected to displacement by applying force in positive $\mathrm{X}$ and negative $\mathrm{X}$ direction and the sensitivity of $\mathrm{X}$ Axis Bridge was found to be around $3 \mathrm{mV} / \mathrm{mm}$ as shown in Table 2 .

During the operation, electrical output voltage of Wheatstone bridge was found to be in milivolts and the same was strengthened using instrumentation amplifier LT 1167 which was designed to give a gain of 110 as shown in Figure 11 after minimizing the offset voltage.

Table 3 shows the amplified output voltage of $\mathrm{Y}$ axis Wheatstone bridge for the applied force in negative $\mathrm{Y}$ direction after minimizing the offset output voltage. The offset voltage which was $356.60 \mathrm{mV}$ is minimized to $18.80 \mathrm{mV}$ by balancing Wheatstone bridge.

\subsection{Dynamic Calibration}

The dynamic characterization of the device is measured by vibration platform. The device is fixed on the vice and the plastic rod was vibrated by using the vibration given by vibration platform in vertical direction. The change in output voltage of the device with the frequency was observed. Figure 12 shows the entire experimental set up of dynamic calibration. With the help of vibration platform, the sensor was subjected to various frequencies ranging from $10 \mathrm{~Hz}$ to 500 $\mathrm{Hz}$ for $\mathrm{g}=0.5$ and $\mathrm{g}=0.2$. The output response of the sensor at $50 \mathrm{~Hz}$ and 100 $\mathrm{Hz}$ for $\mathrm{g}=0.5$ are as shown in Figure 13. The vibration platform experimental set up gave a response in the frequency range of $10 \mathrm{~Hz}$ to $500 \mathrm{~Hz}$ and the resonance frequency was found to be around $80 \mathrm{~Hz}$. 


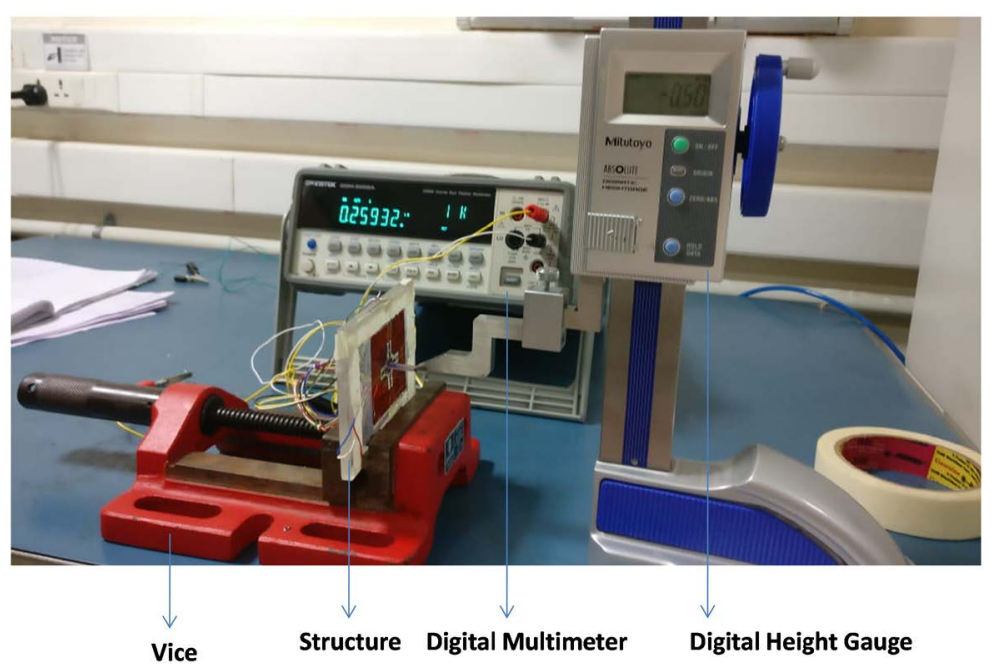

Figure 9. Static Calibration setup with digital height gauge to measure elcetrical output voltage corresponding to the displacement given to the plastic rod in particular direction using digital height gauge.
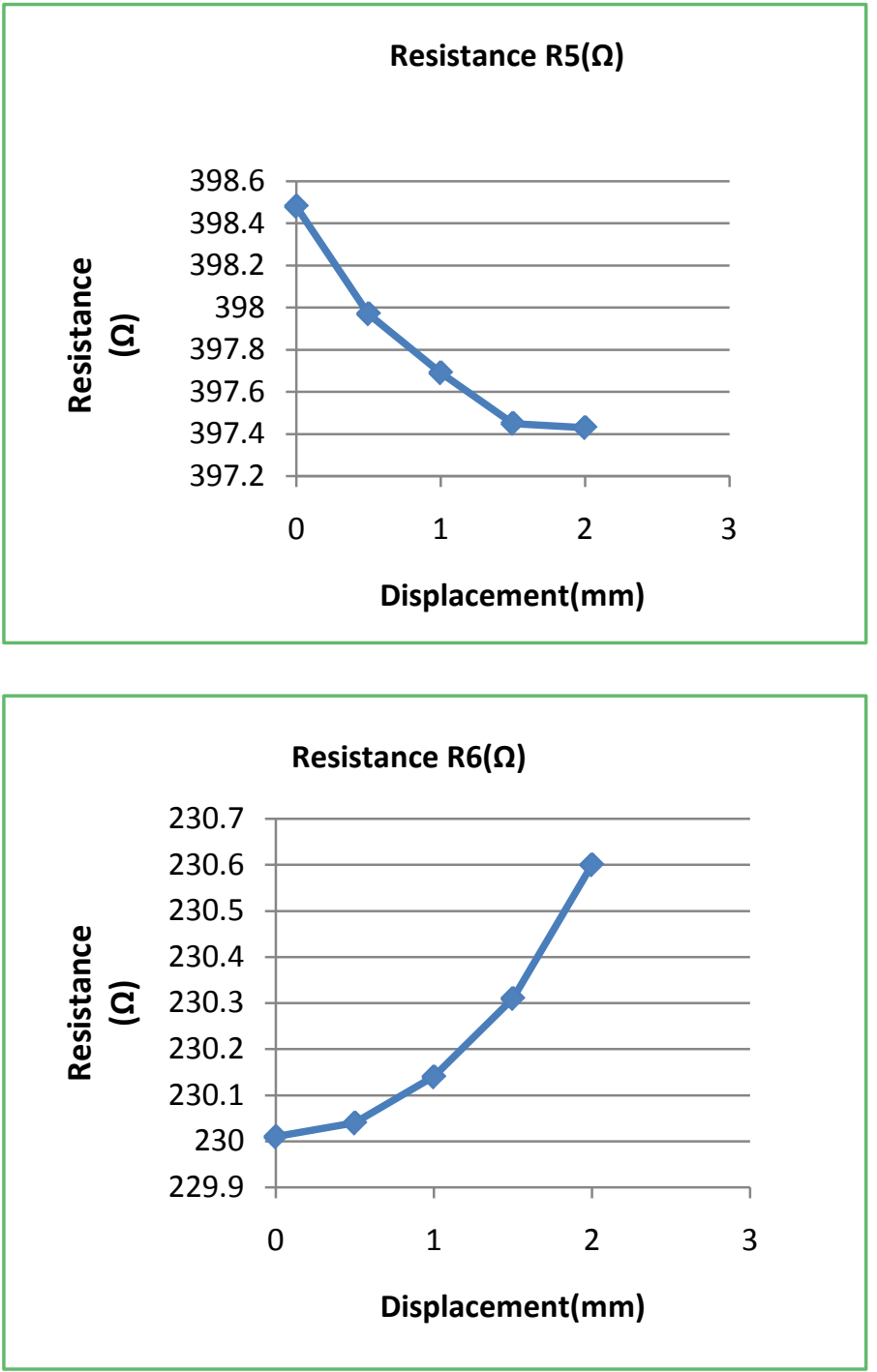

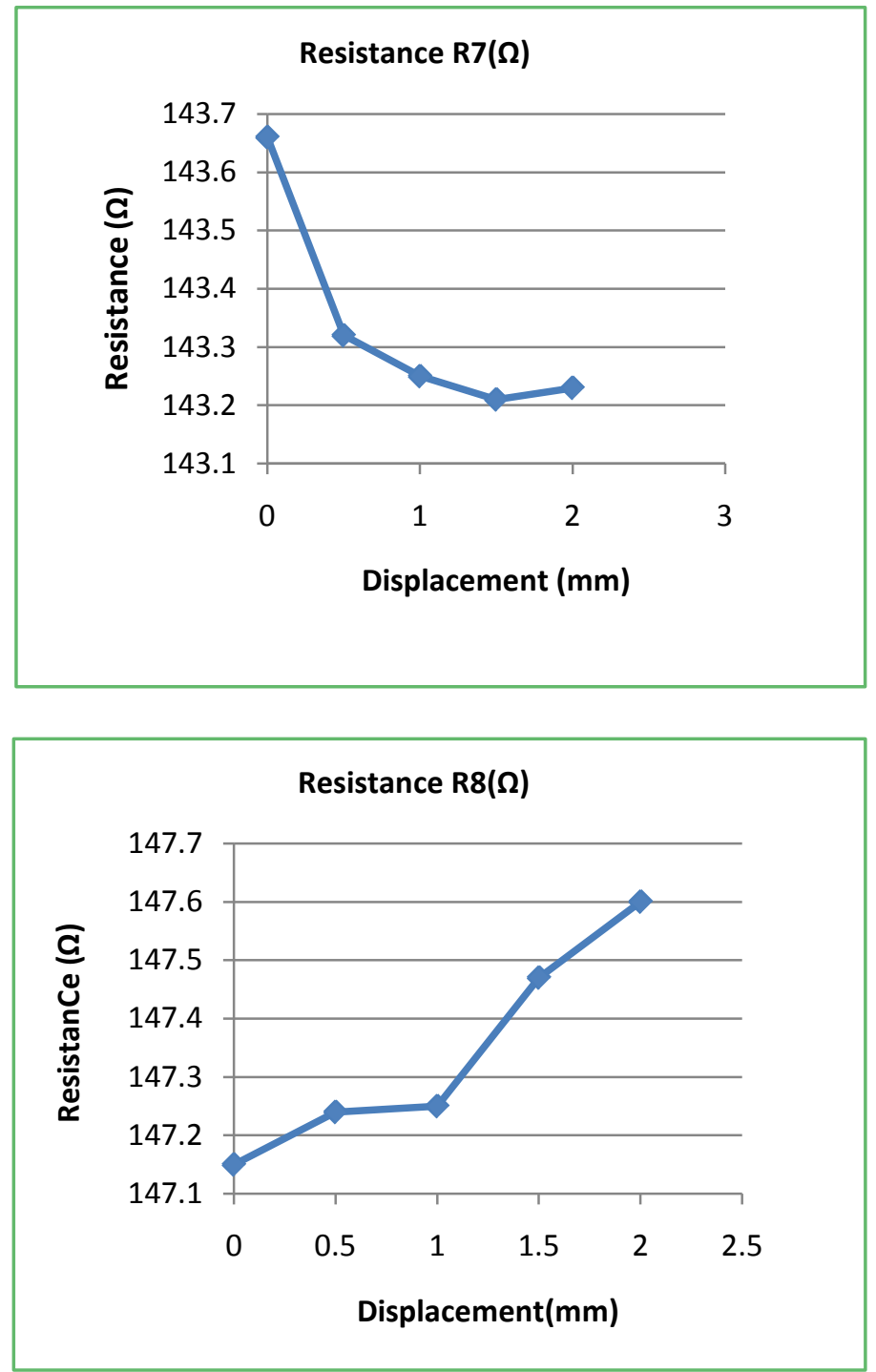

Figure 10. Variation of resistances of $\mathrm{Y}$ axis bridge piezoresistors due to compressive and tensile stress along the beam corresponding to given displacment to the plastic rod.

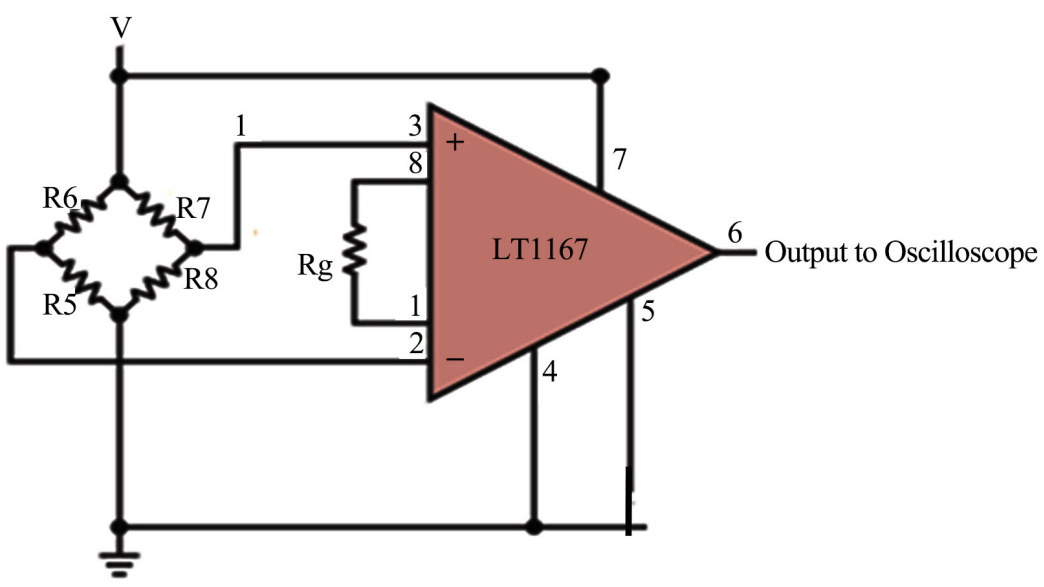

Figure 11. Read-out Circuitry of the Sensor to reuce the offset voltage and to amplify the output voltage by using IC LT1167. 


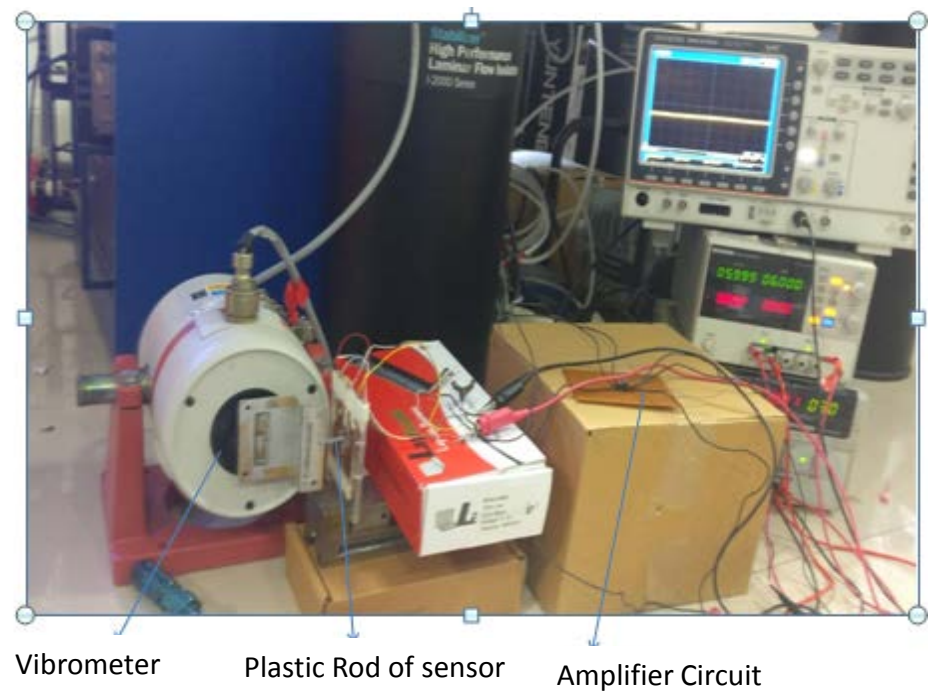

Figure 12. Dynamic calibration setup to measure electrical output voltage corresponding to the vibration given to the plastic rod using vibration platform.

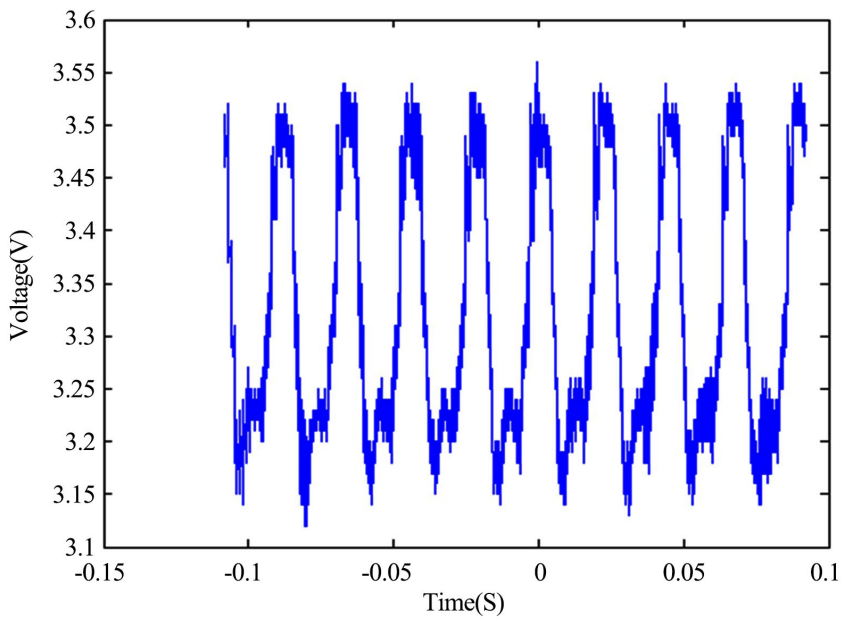

(a)

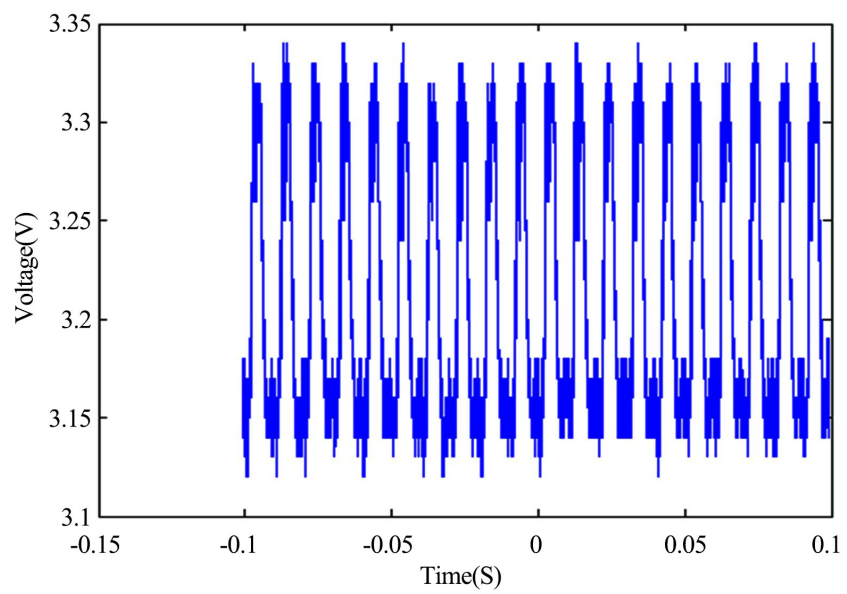

(b)

Figure 13. Dynamic response of a structure for (a) Vibration given to the plastic rod at frequency of $50 \mathrm{~Hz}$; (b) Vibration given to the plastic rod at frequency of $100 \mathrm{~Hz}$. 
Table 1. Electrical output voltage of Y axis heatstone bridge.

\begin{tabular}{ccccc}
\hline $\begin{array}{c}\text { Displacement } \\
(\mathrm{mm})\end{array}$ & $\begin{array}{c}\text { Electrical Output } \\
\text { Voltage }(\mathrm{mV}) \text { for } \\
\text { displacement in } \\
\text { negative } \mathrm{Y} \\
\text { direction }\end{array}$ & $\begin{array}{c}\text { Differential Output } \\
\text { Voltage } \Delta \mathrm{V}(\mathrm{mV}) \\
\text { for displacement in } \\
\text { negative } \mathrm{Y} \\
\text { direction }\end{array}$ & $\begin{array}{c}\text { Electrical Output } \\
\text { Voltage }(\mathrm{mV}) \text { for } \\
\text { displacement in } \\
\text { positive } \mathrm{Y} \\
\text { direction }\end{array}$ & $\begin{array}{c}\text { Differential Output } \\
\text { Voltage } \Delta \mathrm{V}(\mathrm{mV})\end{array}$ \\
$\begin{array}{c}\text { for displacement in } \\
\text { positive } \mathrm{Y} \\
\text { direction }\end{array}$ \\
\hline 0 & 356.60 & 0 & 356.60 & 0 \\
0.5 & 355.50 & 1.1 & 357.75 & 1.15 \\
1 & 354.53 & 2.07 & 358.57 & 1.97 \\
1.5 & 353.57 & 3.03 & 359.52 & 2.92 \\
2 & 352.52 & 4.08 & 360.62 & 4.02 \\
\hline
\end{tabular}

Table 2. Electrical output voltage of $\mathrm{x}$ axis wheatstone bridge.

\begin{tabular}{|c|c|c|c|c|}
\hline $\begin{array}{l}\text { Displacement } \\
\qquad(\mathrm{mm})\end{array}$ & $\begin{array}{l}\text { Electrical Output } \\
\text { Voltage (mV) for } \\
\text { displacement in } \\
\text { negative } \mathrm{X} \\
\text { direction }\end{array}$ & $\begin{array}{l}\text { Differential Output } \\
\text { Voltage } \Delta \mathrm{V}(\mathrm{mV}) \\
\text { for displacement in } \\
\text { negative } \mathrm{X} \\
\text { direction }\end{array}$ & $\begin{array}{l}\text { Electrical Output } \\
\text { Voltage (mV) for } \\
\text { displacement in } \\
\text { positive X } \\
\text { direction }\end{array}$ & $\begin{array}{c}\text { Differential Output } \\
\text { Voltage } \Delta \mathrm{V}(\mathrm{mV}) \\
\text { for displacement in } \\
\text { positive } \mathrm{X} \\
\text { direction }\end{array}$ \\
\hline 0 & 404.32 & 0 & 404.32 & 0 \\
\hline 0.5 & 405.79 & 1.47 & 402.84 & 1.48 \\
\hline 1 & 407.33 & 1.54 & 401.39 & 1.45 \\
\hline 1.5 & 408.91 & 1.58 & 399.89 & 1.5 \\
\hline 2 & 410.41 & 1.5 & 398.37 & 1.52 \\
\hline
\end{tabular}

Table 3. Output voltage of Wheatstone bridge after offset voltage Minimization and amplification for displacement in negative $\mathrm{Y}$ direction.

\begin{tabular}{ccc}
\hline $\begin{array}{c}\text { Displacement } \\
(\mathrm{mm})\end{array}$ & $\begin{array}{c}\text { Electrical Output Voltage (mv) } \\
\text { for displacement in } \\
\text { negative Y direction }\end{array}$ & $\begin{array}{c}\text { Amplified Output Voltage (V) } \\
\text { for displacement in } \\
\text { negative Y direction }\end{array}$ \\
\hline 0 & 18.80 & 2.01 \\
0.5 & 17.51 & 1.90 \\
1 & 16.6 & 1.73 \\
1.5 & 15.59 & 1.69 \\
2 & 14.62 & 1.59 \\
\hline
\end{tabular}

\section{Conclusion}

We have proposed design, simulation, fabrication and preliminary characterization of the two-dimensional Reduced Graphene Oxide based acoustic vector sensor which is suitable for underwater applications. It is observed that the property of graphene is suitable for detection of the sound, when realized on uniform layer of Kapton sensing membrane and also results in simple, low-cost and scalable process. Because of the application of piezoresistive transduction principle, this sensor was found to be best suitable for detection of low-frequency acoustic signals. In addition to the advantages of simple structure, small volume, 
simple process, and low cost of this acoustic vector sensor, it also has good low-frequency characteristics. The resonance frequency of the device is found to be around $80 \mathrm{~Hz}$ and also it exhibits displacement sensitivity around $3 \mathrm{mV} / \mathrm{mm}$ and $2 \mathrm{mV} / \mathrm{mm}$ for $\mathrm{X}$ axis and $\mathrm{Y}$ axis direction respectively. It can be used to estimate the horizontal azimuth of the targets of underwater and can fulfill the requirements for low-frequency sound detection of submarine.

\section{Acknowledgements}

Authors are thankful to the Instrumentation and Applied Physics Department (IAP) and Center for Nano Science and Engineering (CENSE), IISC, Bangalore, for providing the facilities of fabrication, characterization with valuable guidance. Our sincere gratitude tawards Mr. Sankaran and Ms. Pavitra for rendering their help while performing testing of the device.

\section{Conflicts of Interest}

The authors declare no conflicts of interest regarding the publication of this paper.

\section{References}

[1] MIT Sea Grant College Program. Underwater Acoustic. A Brief Introduction by Ethem Mutlu Sozer, Research Engineer.

[2] Au, W.W.L. and Hastings, M. (2009) Principles of Marine Bioacoustics. Springer, Berlin, 27-56.

[3] Liu, M.R., Zhang, G.J. and Song, X.P. (2016) Design of the Monolithic Integrated Array MEMS Hydrophone. IEEE Sensors Journal, 16, 989-995. https://doi.org/10.1109/JSEN.2015.2494617

[4] He, T. and Xu, Z.H. (2010) Piezoelectric Composite Standard Reference Hydrophone for the Frequency Range 100 k-500 kHz. Applied Acoustics, 29, 302-305.

[5] Xue, C.Y., Chen, S., Zhang, W.D., Zhang, B.Z., Zhang, G.J. and Qiao, H. (2007) Design, Fabrication, and Preliminary Characterization of a Novel MEMS Bionic Vector Hydrophone. Microelectronics Journal, 38, 1021-1026. https://doi.org/10.1016/j.mejo.2007.09.008

[6] Zhang, G.J., Liu, L.X., Zhang, W.D. and Xue, C.Y. (2014) Design of a Monolithic Integrated Three-Dimensional MEMS Bionic Vector Hydrophone. Technical Paper, Springer-Verlag, Berlin, Heidelberg. https://doi.org/10.1007/s00542-014-2262-0

[7] Liu, M.R., Zhang, G.J., Jian, Z.M., Liu, H., Song, X.P. and Zhang, W.D. (2014) Design of Array MEMS Vector Vibration Sensor in the Location of Pipeline Internal Inspector. Indonesian Journal of Electrical Engineering, 12, 6651-6657. https://doi.org/10.11591/telkomnika.v12i9.4286

[8] Chen, S., Xue, C.Y., Zhang, B.Z., Xie, B. and Qiao, H. (2007) A Novel MEMS Based Piezoresistive Vector Hydrophone for Low Frequency Detection. 2007 International Conference on Mechatronics and Automation, Harbin, 5-8 August 2007, 1839-1844. https://doi.org/10.1109/ICMA.2007.4303830

[9] Chen, S., Zhang, W.D., Guan, L.G. and Zhang, G.J. (2009) Research of DOA Estimation Based on Single MEMS Vector Hydrophone. Sensors, 9, 6823-6834. https://doi.org/10.3390/s90906823 
[10] Nella, N., Gaddam, V., Nayak, M.M., Rajanna, K. and Srinivas, T. (2015) Highly Flexible and Sensitive Graphene-Silver Nanocomposite Strain Sensor. 2015 IEEE SENSORS, Busan, 1-4 November 2015, 1677-1680. https://doi.org/10.1109/ICSENS.2015.7370612

[11] Cao, K.H., Ye, X.D. and Guo, X.H. (2017) Design and Simulation of Two-Dimensional Graphene-Based Acoustic Sensor Arrays. 2017 IEEE International Ultrasonics Symposium (IUS), Washington DC, 6-9 September 2017. https://doi.org/10.1109/ULTSYM.2017.8091937

[12] Geim, A.K. and Novoselov, K.S. (2007) The Rise of Graphene. Nature Materials, 6, 183-191. https://doi.org/10.1038/nmat1849 